\title{
In vivo laser confocal microscopy findings in patients with map-dot-fingerprint (epithelial basement membrane) dystrophy
}

This article was published in the following Dove Press journal:

Clinical Ophthalmology

26 July 2012

Number of times this article has been viewed

\section{Akira Kobayashi \\ Hideaki Yokogawa \\ Kazuhisa Sugiyama}

Department of Ophthalmology, Kanazawa University Graduate School of Medical Science, Kanazawa, Japan
Correspondence: Akira Kobayashi Department of Ophthalmology, Kanazawa University Graduate School of Medical Science, I3-I Takara-machi, Kanazawa, Ishikawa 920-864I, Japan

Tel +8I7 62652403

Fax +81762229660

Email kobaya@kenroku.kanazawa-u.ac.jp
Background: The purpose of this study was to investigate pathological changes of the corneal cell layer in patients with map-dot-fingerprint (epithelial basement membrane) dystrophy by in vivo laser corneal confocal microscopy.

Methods: Two patients were evaluated using a cornea-specific in vivo laser scanning confocal microscope (Heidelberg Retina Tomograph 2 Rostock Cornea Module, HRT 2-RCM). The affected corneal areas of both patients were examined. Image analysis was performed to identify corneal epithelial and stromal deposits correlated with this dystrophy.

Results: Variously shaped (linear, multilaminar, curvilinear, ring-shape, geographic) highly reflective materials were observed in the "map" area, mainly in the basal epithelial cell layer. In "fingerprint" lesions, multiple linear and curvilinear hyporeflective lines were observed. Additionally, in the affected corneas, infiltration of possible Langerhans cells and other inflammatory cells was observed as highly reflective Langerhans cell-like or dot images. Finally, needle-shaped materials were observed in one patient.

Conclusion: HRT 2-RCM laser confocal microscopy is capable of identifying corneal microstructural changes related to map-dot-fingerprint corneal dystrophy in vivo. The technique may be useful in elucidating the pathogenesis and natural course of map-dot-fingerprint corneal dystrophy and other similar basement membrane abnormalities.

Keywords: cornea, confocal microscopy, map-dot-fingerprint dystrophy, epithelial basement membrane dystrophy, Heidelberg Retina Tomograph 2 Rostock Cornea Module (HRT 2-RCM)

\section{Introduction}

Map-dot-fingerprint (epithelial basement membrane) dystrophy (OMIM 121820) ${ }^{1}$ is a bilateral anterior corneal dystrophy that usually develops between the ages of 20 and 40 years, and is characterized by grayish epithelial fingerprint lines, geographic map-like lines, and dots (or microcysts) on slit-lamp examination. ${ }^{2-4}$ Findings are variable and can change with time. Although map-dot-fingerprint dystrophy is usually asymptomatic, about $10 \%$ of patients develop painful, recurrent epithelial erosions. In some families, this condition appears to segregate as a true autosomal dominant trait. ${ }^{5}$ However, Werblin et al reported that map-dot-fingerprint dystrophy is present in up to $76 \%$ of persons over the age of 50 years, suggesting that most cases of this condition represent age-dependent degeneration of the cornea. ${ }^{6}$

In vivo white light corneal confocal microscopy allows noninvasive real-time spatial sectioning of living corneal tissues at the cellular level. ${ }^{7,8}$ The clinical usefulness of this method has been documented in studies of both normal and diseased human corneas. ${ }^{9-11}$ Recently, cornea-specific in vivo laser confocal microscopy (Heidelberg Retina Tomo- 
graph 2 Rostock Cornea Module, HRT 2-RCM, Heidelberg Engineering GmbH, Dossenheim, Germany) has become available and allowed more detailed in vivo observation of corneal microstructure, ${ }^{12,13}$ including map-dot-fingerprint dystrophy. ${ }^{14,15}$ In this study, we investigated pathological changes of the corneal cell layer in patients with map-dotfingerprint dystrophy by in vivo laser corneal confocal microscopy.The possible association of this dystrophy with corneal inflammation is discussed.

\section{Materials and methods}

The present study was approved by the ethics committee of Kanazawa University Graduate School of Medical Science and followed the tenets of the Declaration of Helsinki. Two patients (cases 1 and 2) with map-dot-fingerprint dystrophy, neither of whom had a known family history of the disorder, underwent in vivo laser confocal microscopic examination (HRT 2-RCM) at the Department of Ophthalmology, Kanazawa Graduate University of Medical Science.

\section{In vivo laser confocal microscopic observation}

Prior to beginning this study, written informed consents were obtained from both subjects after explaining the nature and possible consequences of this study. After applying a large drop of contact gel (Comfort Gel ophthalmic ointment ${ }^{\circledR}$, Bausch and Lomb, GmbH, Berlin, Germany) on the front surface of the microscope lens and ensuring that no air bubbles had formed, a Tomo-cap ${ }^{\circledR}$ (Heidelberg Engineering $\mathrm{GmbH}$ ) was mounted on the holder to cover the microscope lens. The center and peripheral cornea were then examined layer by layer using this cornea-specific in vivo laser confocal microscope. HRT 2-RCM uses a 60× water-immersion objective lens (Olympus Europa GmbH, Hamburg, Germany) and a $670 \mathrm{~nm}$ diode laser as the light source with an area of observation of $400 \mu \mathrm{m}$ square section. ${ }^{16}$

\section{Patients}

\section{Case I}

A 60-year-old woman with mild hypertension and background diabetic retinopathy visited our hospital for routine ophthalmic examination. Her corrected visual acuity was 20/40 in both eyes. The intraocular pressure was $11.4 \mathrm{mmHg}$ and $11.8 \mathrm{mmHg}$ in the right and left eye, respectively. By slit-lamp biomicroscopy, geographic-shaped abnormalities were observed in the Bowman's membrane level in both eyes (Figure 1A). She had a mild cataract in both eyes. Her family history was unremarkable. No other abnormalities were
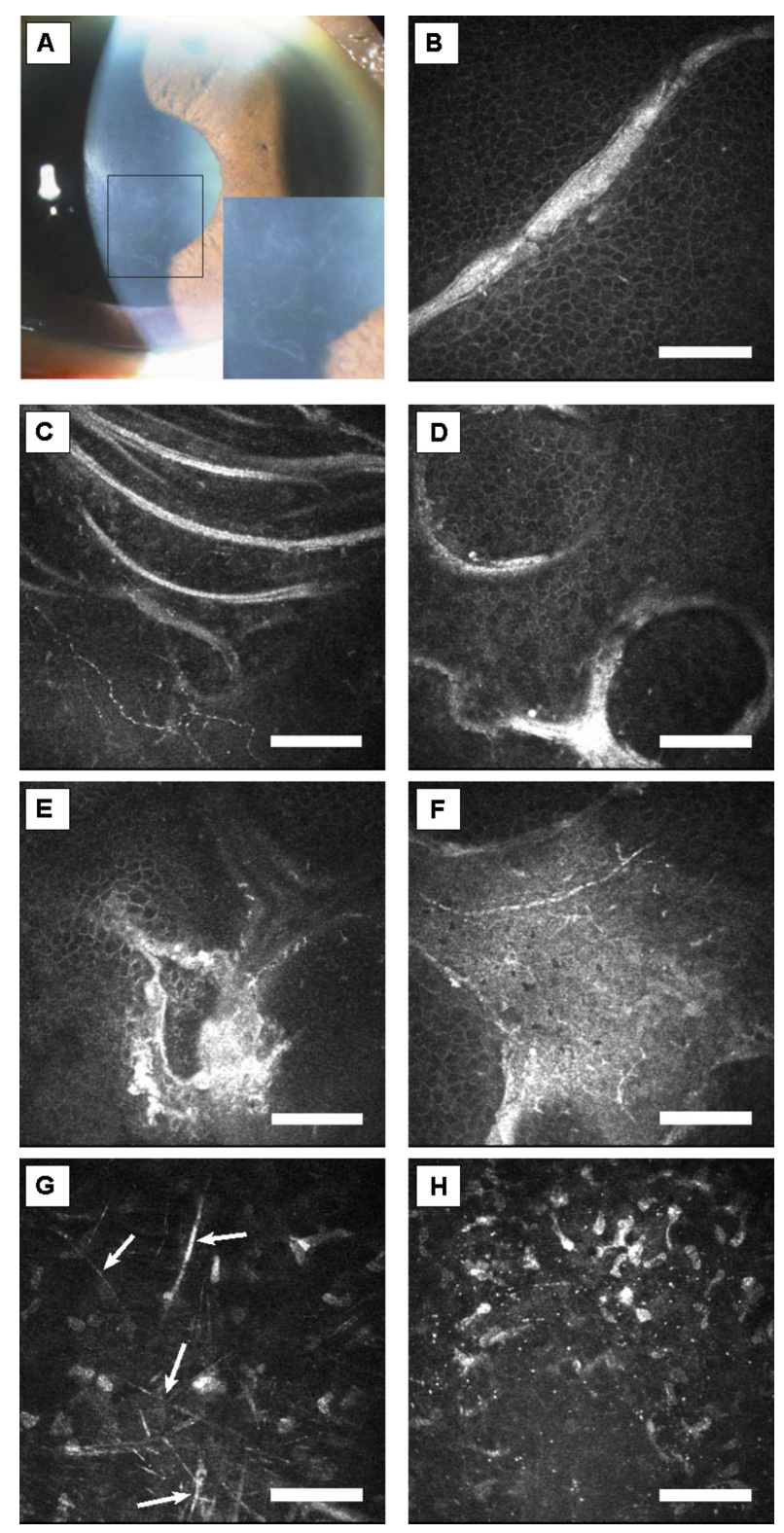

Figure I Case I. (A) Slit-lamp photograph of right cornea. Geographic-shaped abnormalities in the central cornea are magnified in the lower right box. (B) In vivo laser confocal microscopic images of corneal lesions. Highly reflective linear images in the basal epithelium (depth $28 \mu \mathrm{m}$ ). (C) Highly reflective curvilinear, multilaminar lines in the basal epithelium (depth $20 \mu \mathrm{m}$ ). (D) Ring-shaped highly reflective extracellular deposits in the basal epithelium (depth $25 \mu \mathrm{m}$ ). (E) Highly reflective irregular deposit in the basal epithelium (depth $29 \mu \mathrm{m}$ ). (F) Highly reflective geographic opacities in the basal epithelial layer (depth $22 \mu \mathrm{m}$ ). (G) Highly reflective needleshaped structures were also observed in the stroma (arrows, depth $445 \mu \mathrm{m}$ ). (H) Highly reflective microdots were observed in the stroma (depth $74 \mu \mathrm{m}$ ). Note: Bar $100 \mu \mathrm{m}$.

detected by dilated fundus examination. She had no history of recurrent corneal erosions.

\section{Case 2}

A 44-year-old man who was otherwise healthy visited our hospital for further evaluation of recurrent corneal erosions. His corrected visual acuity was 20/20 in both eyes. 
The intraocular pressure was $14.8 \mathrm{mmHg}$ and $16.0 \mathrm{mmHg}$ in the right and left eye, respectively. By slit-lamp biomicroscopy, fingerprint-shaped abnormalities were observed in the Bowman's membrane level in both eyes (Figure 2A). He had had a painful corneal erosion in his right eye two years prior to our appointment, and he had a similar event in his left eye one month prior to his appointment. His family history was also unremarkable. No other abnormalities were detected by dilated fundus examination.

\section{Results}

\section{In vivo laser confocal microscopy}

In case 1, microscopy of the affected lesions ("map") of the cornea revealed various shapes of highly reflective extracellular deposits in the superficial/basal epithelium and Bowman's
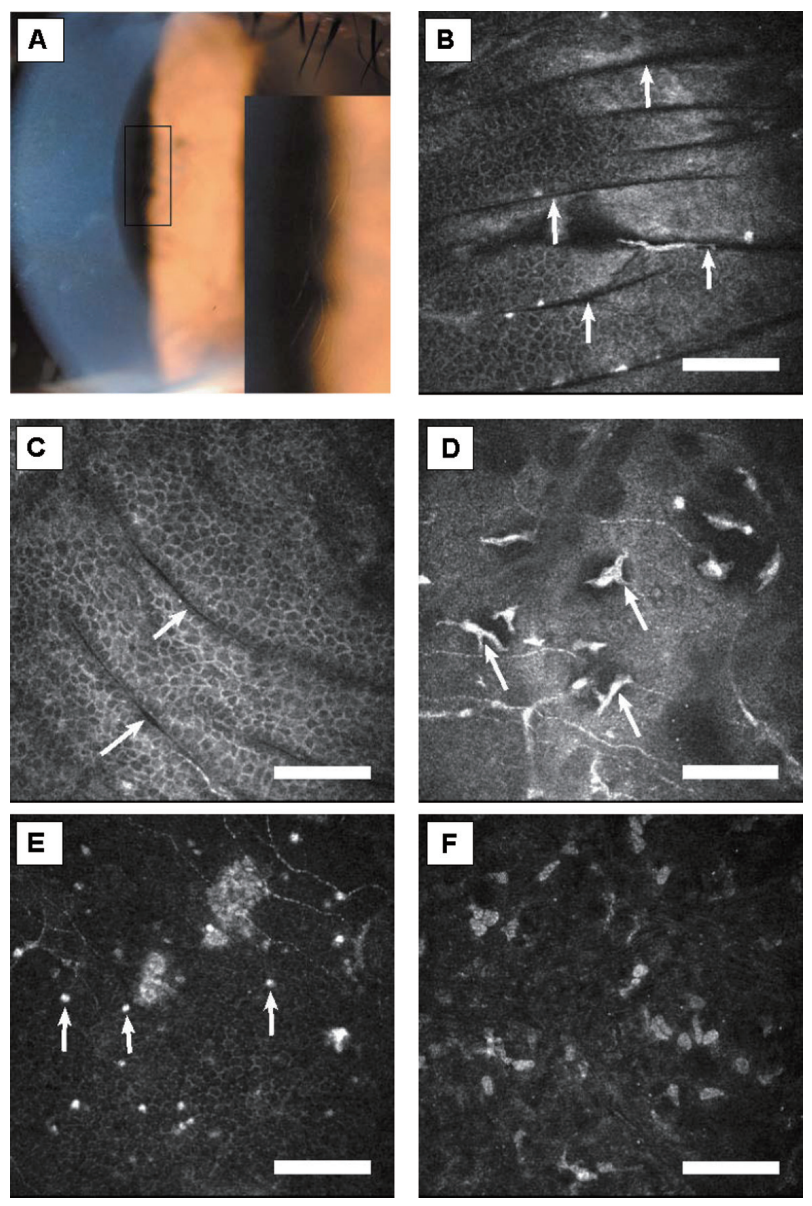

Figure 2 Case 2. (A) Slit-lamp photograph of right cornea. Fingerprint-shaped abnormalities in the central cornea are magnified in the lower right box. (B and $\mathbf{C}$ ) In vivo laser confocal microscopic images of corneal lesions. Multiple dark parallel striae in the superficial/basal epithelium and Bowman's membrane layer (arrows, depth $22 \mu \mathrm{m}$ and $25 \mu \mathrm{m}$, respectively). (D) Infiltration of possible Langerhans cells in Bowman's membrane cell layer (depth $5 \mathrm{I} \mu \mathrm{m}$, arrows). (E) Highly reflective dots were observed in the basal epithelial layer (depth $60 \mu \mathrm{m}$, arrows). (F) Highly reflective microdots were observed in the stroma (depth $80 \mu \mathrm{m}$ ).

Note: Bar $100 \mu \mathrm{m}$. membrane layer (Figure 1B-F). In the stroma, highly reflective needle-shaped structures (Figure $1 \mathrm{G}$ together with microdots in Figure 1H) were observed. Descemet's membrane and the endothelial cell layer appeared normal.

In case 2, microscopy of the affected lesions ("fingerprints") of the cornea revealed multiple dark striae in the superficial/ basal epithelium and Bowman's membrane layer (Figure 2B and C). Infiltration of possible Langerhans cells and highly reflective dots were also observed in Bowman's membrane layer (Figure 2D and E). In the stroma, highly reflective microdots were observed (Figure 2F). Descemet's membrane and the endothelial cell layer appeared normal.

\section{Discussion}

We have now reported in vivo laser confocal microscopic images in patients with map-dot-fingerprint (epithelial basement membrane) dystrophy. In the epithelial/Bowman's membrane layer, variously shaped (linear, multilaminar, curvilinear, ring-shape, geographic) highly reflective materials were observed in the "map" area. In the same layer as the "fingerprint" lesions, multiple linear and curvilinear hyporeflective lines were observed. The novel aspect of this study is that we reported stromal changes of this dystrophy, such as highly reflective microdots and needle-shaped materials; these changes have not been reported previously. ${ }^{14,15}$

The histopathologic finding of "map" and "fingerprint" lesions represents a thickened epithelial basement membrane that has invaginated into the epithelium in the form of multilaminar sheets of fibrogranular material. ${ }^{3,17-19}$ We surmise that the various shapes of highly reflective images in the epithelial/Bowman's membrane layer identified on HRT 2-RCM might correspond with fibrogranular materials at the scalloped borders or inside the lesions of map-shaped subepithelial opacities. Also, the multiple linear and curvilinear hyporeflective lines in the fingerprint lesions might correspond with invagination of the abnormal redundant basement membrane. These lesions could be due to the artifacts during operation; however, we did not observe these artifacts among hundreds of patients studied previously. Taken altogether, in vivo laser confocal microscopic images obtained by HRT 2-RCM seem to correlate very well with previously reported histopathological changes in map-dotfingerprint dystrophy.

Classically, two clinically and histopathologically distinct types of "dot" lesions have been reported, ie, Cogan cysts and the cysts reported by Bron and Brown. ${ }^{18,20,21}$ Cogan cysts are characterized by intraepithelial cystic aggregations of degenerating cells underneath an intraepithelial sheet. 
The histopathology of the second cyst type is thought to be a continuous layer of fibrillogranular material located between the epithelial basement membrane and Bowman's layer, not a product of cellular degeneration. Neither patient we examined for this study had any microcysts on slit-lamp examination. Therefore, in vivo confocal images of microcysts could not be obtained in this study.

The precise origin of the needle-shaped material has not been identified; however, it can be seen in the early and late phase of corneal inflammation. ${ }^{11}$ We also observed possible Langerhans cells and other inflammatory cells in the superficial corneas of both patients. Taken together, these potential inflammatory components observed in corneas affected by map-dot-fingerprint dystrophy lead us to suspect an association of this dystrophy with inflammation. A possible explanation of the inflammatory changes is that they might be due to a secondary response caused by previous corneal erosions and/or deposition of fibrogranular materials.

In conclusion, HRT 2-RCM is capable of identifying in vivo corneal microstructural changes related to map-dotfingerprint corneal dystrophy with higher resolution than is possible with slit-lamp biomicroscopy. We could identify unique and characteristic images of corneal deposits not only in the epithelial cell/Bowman's layer level, but also in the stroma. Thus, HRT 2-RCM may be useful in elucidating the pathogenesis and natural course of map-dot-fingerprint corneal dystrophy and other similar basement membrane abnormalities.

\section{Disclosure}

The authors report no conflicts of interest in this work.

\section{References}

1. Online Mendelian Inheritance in Man. Baltimore, MD: Johns Hopkins University; 2004. Available from: http://www.ncbi.nlm.nih.gov/omim/. Accessed July 4, 2012.

2. Cogan DG, Donaldson DD, Kuwabara T, Marshall D. Microcystic dystrophy of the corneal epithelium. Trans Am Ophthalmol Soc. 1964;62:213-225.

3. Cogan DG, Kuwabara T, Donaldson DD, et al. Microcystic dystrophy of the cornea: a partial explanation for its pathogenesis. Arch Ophthalmol. 1974;92:470-474.

Clinical Ophthalmology

\section{Publish your work in this journal}

Clinical Ophthalmology is an international, peer-reviewed journal covering all subspecialties within ophthalmology. Key topics include: Optometry; Visual science; Pharmacology and drug therapy in eye diseases; Basic Sciences; Primary and Secondary eye care; Patient Safety and Quality of Care Improvements. This journal is indexed on Submit your manuscript here: http://www.dovepress.com/clinical-ophthalmology-journal
4. Irvine AD, Wang MX, McLean WH. Epithelial, basement membrane, and Bowman's membrane layer dystrophies. In: Wang MX, editor. Corneal Dystrophies and Degenerations: A Molecular Genetic Approach. New York, NY: Oxford University Press; 2003.

5. Laibson PR, Krachmer JH. Familial occurrence of dot (microcystic), map, fingerprint dystrophy of the cornea. Invest Ophthalmol. 1975;14:397-399.

6. Werblin TP, Hirst LW, Stark WJ, Maumenee IH. Prevalence of map-dot-fingerprint changes in the cornea. Br J Ophthalmol. 1981;65:401-409.

7. Cavanagh HD, Petroll WM, Alizadeh H, et al. Clinical and diagnostic use of in vivo confocal microscopy in patients with corneal disease. Ophthalmology. 1993;100:1444-1454.

8. Kaufman SC, Musch DC, Belin MW, et al. Confocal microscopy: a report by the American Academy of Ophthalmology. Ophthalmology. 2004;111:396-406.

9. Kobayashi A, Sugiyama K. In vivo corneal confocal microscopic findings of palisades of Vogt and its underlying limbal stroma. Cornea. 2005;24:435-437.

10. Kobayashi A, Sugiyama K, Huang AJ. In vivo confocal microscopy in patients with central cloudy dystrophy of Francois. Arch Ophthalmol. 2004;122:1676-1679.

11. Kobayashi A, Maeda A, Sugiyama K. In vivo confocal microscopy in the acute phase of corneal inflammation. Ophthalmic Surg Lasers Imaging. 2003;34:433-436.

12. Stave J, Zinser G, Grummer G, Guthoff R. Modified Heidelberg Retinal Tomograph HRT. Initial results of in vivo presentation of corneal structures. Ophthalmologe. 2002;99:276-280. German.

13. Kobayashi A, Yoshita T, Sugiyama K. In vivo findings of bulbar/ palpebral conjunctiva and presumed meibomian gland by laser scanning confocal microscopy. Cornea. 2005;24:985-988.

14. Labbé A, Nicola RD, Dupas B, Auclin F, Baudouin C. Epithelial basement membrane dystrophy: evaluation with the HRT II Rostock Cornea Module. Ophthalmology. 2006;113:1301-1308.

15. Rosenberg ME, Tervo TM, Petroll WM, Vesaluoma MH. In vivo confocal microscopy of patients with corneal recurrent erosion syndrome or epithelial basement membrane dystrophy. Ophthalmology. 2000;107:565-573.

16. Heidelberg Retina Tomograph II (Rostock Cornea Module) Operating Instructions of Software Version 1.1. Dossenheim, Germany: Heidelberg Engineering GmbH; 2004.

17. Laibson PR. Microcystic corneal dystrophy. Trans Am Ophthalmol Soc. 1976;74:488-531.

18. Bron AJ, Brown NA. Some superficial corneal disorders. Trans Ophthalmol Soc U K. 1971;91:XII+.

19. Rodrigues MM, Fine BS, Laibson PR, et al. Disorders of the corneal epithelium: a clinicopathologic study of dot, geographic, and fingerprint patterns. Arch Ophthalmol. 1974;92:475-482.

20. Bron AJ, Tripathi RC. Cystic disorders of the corneal epithelium I: clinical aspects. Br J Ophthalmol. 1973;57:361-375.

21. Tripathi RC, Bron AJ. Cystic disorders of the corneal epithelium II: pathogenesis. Br J Ophthalmol. 1973;57:376-390.
PubMed Central and CAS, and is the official journal of The Society of Clinical Ophthalmology (SCO). The manuscript management system is completely online and includes a very quick and fair peer-review system, which is all easy to use. Visit http://www.dovepress.com/ testimonials.php to read real quotes from published authors. 